\title{
Posterior Stabilization of Unstable Sacral Fractures: A Single-Center Experience of Percutaneous Sacroiliac Screw and Lumbopelvic Fixation in 67 Cases
}

\author{
Ajoy Prasad Shetty, Karukayil Ramakrishnan Renjith, Ramesh Perumal, Sri Vijay Anand, \\ Rishi Mugesh Kanna, Shanmuganathan Rajasekaran \\ Department of Spine Surgery, Ganga Medical Centre \& Hospital Pvt. Ltd., Coimbatore, India
}

\begin{abstract}
Study Design: This is a retrospective study.
Purpose: Recent advances in intraoperative imaging and closed reduction techniques have led to a shifting trend toward surgical management in every unstable sacral fracture. This study aimed to evaluate the clinicoradiological outcome of the sacroiliac (SI) screw and lumbopelvic fixation (LPF) techniques and thereby delineate the indications for each.

Overview of Literature: Optimal management guidelines for unstable sacral fractures are still lacking probably due to the rarity of these injuries and varying fixation trends.

Methods: Out of the 67 patients, 40 and 27 were in the SI and LPF groups, respectively. The electronic medical record for each patient was reviewed, including patient demographic data, mode of trauma, coexisting injuries, neurological status (Gibbon's four-grade system), Injury Severity Score, time from admission to operative stabilization, type of surgical stabilization, complications, return to the operating room, and treatment outcome measures using Majeed's functional grading system and Matta's radiological criteria. The minimum follow-up period was 2 years.

Results: Noncomminuted longitudinal injuries with normal neurology and acceptable closed reduction have undergone SI screw fixation ( $n=40)$. Irreducible, comminuted, or high transverse fractures associated with dysmorphic anatomy or neurodeficit were managed by LPF ( $n=27)$. Excellent and good Majeed and Matta scores at $86.57 \%$ and $92.54 \%$ of the patients, respectively, were postoperatively achieved.

Conclusions: Unstable sacral fractures can be effectively managed with percutaneous SI screw including vertically unstable injuries by paying strict attention to preoperative patient selection whereas LPF can be reserved for comminuted fractures, unacceptable closed reduction, associated neurodeficit, lumbosacral dysmorphism, and high transverse fractures.
\end{abstract}

Keywords: Unstable sacral fractures; Spinopelvic dissociation; Surgical management; Lumbopelvic fixation; Sacroiliac screw

Received Jun 28, 2020; Revised Sep 11, 2020; Accepted Sep 13, 2020

Corresponding author: Ajoy Prasad Shetty

Department of Spine Surgery, Ganga Medical Centre \& Hospital Pvt. Ltd., Coimbatore, Tamil Nadu, India

Tel: +91-9344833797, Fax: +91-422241444, E-mail: ajoyshetty@gmail.com 


\section{Introduction}

The management of unstable sacral fractures, especially those with associated multisystem injuries and overlapping fracture patterns, is a challenge even to the most experienced surgeon. Any sacral fracture with associated posterior pelvic ring disruption is deemed unstable, and vertical instability, being the worst, warrants surgical stabilization. Spinopelvic dissociation is a relatively newer terminology that represents a spectrum of highly complex atypical sacral fractures resulting in multiplanar instability of the lumbopelvic. Optimal management guidelines are still lacking probably due to the rarity of these injuries and varying fixation trends.

Among the surgical techniques described for sacral fractures like sacroiliac (SI) screws, posterior tension band plating, and transiliac rods among others, lumbopelvic fixation (LPF) with or without percutaneous SI screws has surpassed all other techniques, and their combination, otherwise known as "triangular osteosynthesis", is reported to have the greatest mechanical stability [1]. The description of closed reduction and minimally invasive strategies has popularized LPF and is the preferred option for spinopelvic dissociation.

Although the advantages of LPF have been proven clinically and biomechanically in rotationally and vertically unstable injuries not amenable to SI screw fixation, a rising trend exists toward its routine use in every unstable sacral fracture [2]. LPF is considered an overtreatment adding to surgical morbidity especially in patients with multisystem afflictions unless indicated [3]. Moreover, a steep learning curve, loss of motion segments, and implant-related complications further deter its routine use. This study sought to evaluate the outcome of SI screw and LPF strategies in unstable sacral fractures and thereby delineate the indications for each.

\section{Materials and Methods}

\section{Patients}

After obtaining approval of the Institutional Review Board of Ganga Medical Centre and Hospitals Pvt. Ltd., Coimbatore (IRB approval no., 2019/11/11; dated 13/11/2019) and informed consent, 75 consecutive adult patients (range, 18-50 years) who underwent surgical management for traumatic sacral fractures at the hospital be- tween January 2013 and December 2017 with a minimum follow-up of 2 years were retrospectively reviewed. All patients having unstable sacral fracture and associated pelvic ring injury, open or closed, unilateral or bilateral, with or without neurodeficit were included. Isolated SI joint and pelvic injuries without sacral fractures were excluded. Five patients were lost to follow-up, and three patients were excluded due to incomplete radiographic imaging. Thus, 67 patients constituted the final study group (48 males and 19 females). Based on the surgical technique employed, the study population was divided into the SI and LPF groups. Electronic medical records were reviewed and recorded, including patient demographic data, mode of trauma, coexisting injuries, neurological status (Gibbon's four-grade system), Injury Severity Score (ISS), time from admission to operative stabilization, type of surgical stabilization, complications, return to the operating room, and treatment outcome measures [4].

All patients were initially evaluated according to the Advanced Trauma Life Support protocol. After stabilization of the general condition, plain X-rays of the pelvis (anterior-posterior/inlet-outlet views) and computed tomography (CT) scan with three-dimensional reconstruction were preoperatively taken to determine fracture morphology. The Denis and Roy-Camille classification systems were used for sacral fractures along with morphological types like the $\mathrm{H}, \mathrm{T}, \mathrm{U}$, and lambda types, whereas pelvic stability was assessed as per the Young and Burgess classification system [5-8]. Denis zone II and III injuries and Young-Burgess anterior-posterior compression (APC; types II and III), lateral compression (types II and III), and vertical shear injuries were considered indications for surgery. Preoperative distal femoral skeletal traction was applied in all cases with vertical shear injuries. Anterior stabilization when indicated (displaced pubic rami fractures, $>10 \mathrm{~mm}$; pubic diastasis, $>20 \mathrm{~mm}$ ) was done first using symphyseal reconstruction plating, pubic rami screws, or infix (anterior subcutaneous internal fixation using bilateral supracetabular pedicle screws through anterior inferior iliac spine connected via a subcutaneous contoured rod) followed by posterior fixation.

\section{Surgical technique}

1) Sacroiliac screw

Standardized percutaneous technique in the prone position was used for SI screw fixation. The decision to use 
single or dual screws and its length were taken preoperatively by the senior author depending on screw purchase and fracture morphology.

Indications: noncomminuted longitudinal fractures, acceptable closed reduction with a residual displacement $<1$ $\mathrm{cm}$, absence of neurodeficit/lumbosacral dysmorphism, absence of high transverse fracture (Fig. 1) [9].

\section{2) Lumbopelvic fixation}

LPF was performed by a paraspinal approach in unilateral injuries with normal neurology (midline approach for bilateral injuries/neurodeficit) using L4/L5 pedicle screw (extension to L4 in L5 pedicle fracture/L4-5 pre-existing instability), iliac screw, and connecting rod.

Indications: neurological deficit, comminuted sacral fracture, lumbosacral dysmorphism, an extension of fracture into the L5-S1 facet, high transverse fractures, and failure of closed reduction (Fig. 2).

\section{3) Reduction technique}

Vertical displacement was reduced by distal femoral traction whereas rotational correction was obtained by an associated hip external rotation. In the case of transverse fractures, the postural reduction was achieved by keeping pillows under the thighs to assist pelvis extension while intraoperative maneuvers included bifemoral traction and lumbopelvic distraction.

\section{4) Postoperative care}

Immediate postoperatively, all patients were allowed to move in bed with a strict emphasis on pelvic lifting and quadriceps/ankle exercises. The patients were given deep venous thrombosis prophylaxis in the form of intermittent pneumatic compression device and low-molecular-weight heparin followed by low-dose aspirin at the time of discharge for 6 weeks. Case-sensitive, gradual weight-bearing on crutches was allowed 3 weeks after the operation except in spinopelvic dissociation and/or vertical instability. Full weight-bearing was allowed after postoperative week 6 depending on the follow-up X-ray. Patients were examined at 3 weeks, 6 weeks, 3 months, 6 months, 9 months, and 12 months following hospital discharge and every 6 months thereafter. The minimum follow-up period was 2 years.

Complications such as infection, neurodeterioration, loss of fixation, hardware prominence, non-union, and unplanned return to the operating room were recorded. At the final follow-up, all patients had a detailed neurolog-
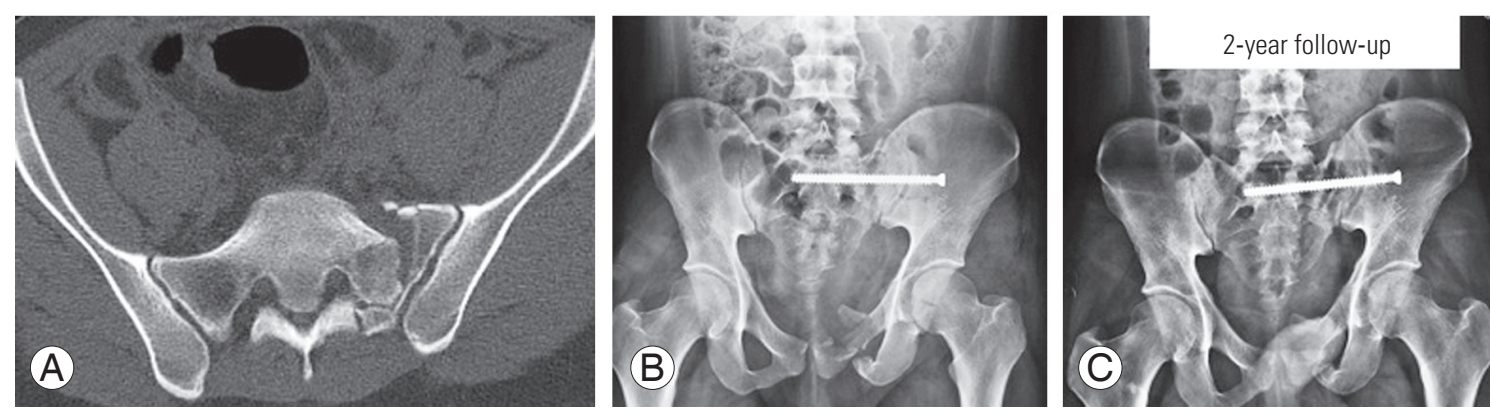

Fig. 1. (A-C) Preoperative computed tomography scan and postoperative anterior-posterior radiographs of a 25-year-old male showing Denis zone-2 injury managed by sacro-iliac screw.
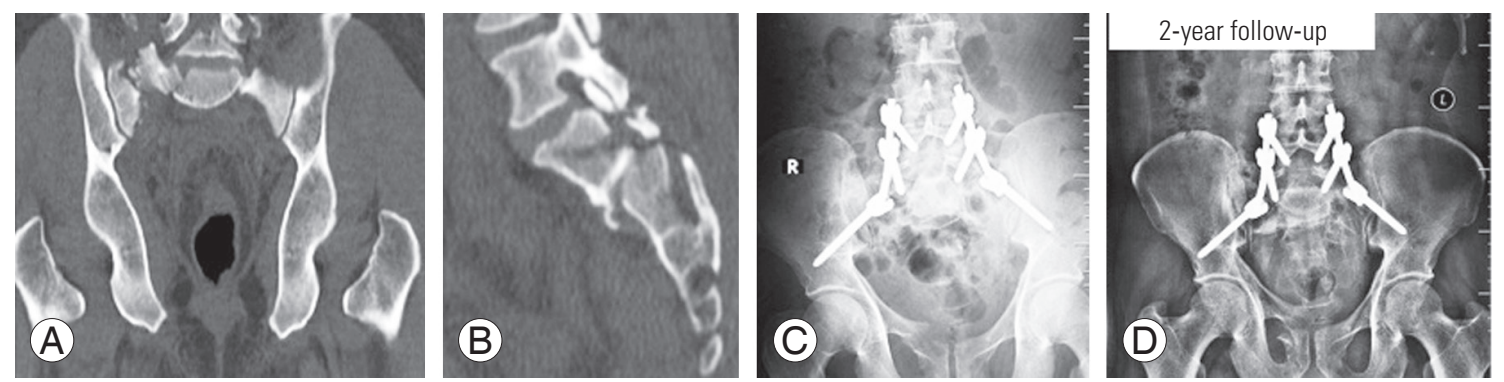

Fig. 2. (A-D) Preoperative computed tomography scan and postoperative radiographs of a 16-year-old male showing Roy-Camille type-2 injury managed by lumbo-pelvic fixation. 
ical evaluation along with functional outcome assessment using Majeed's grading system and radiological evaluation using the Matta criteria and pelvic incidence (in case of transverse fractures) $[9,10]$.

\section{Statistical analysis}

The SPSS ver. 17.0 software (SPSS Inc., Chicago, IL, USA) was used for statistical analysis. Results are presented as mean \pm standard deviation values and frequency as numbers (in percent). The $Z$-test for proportions was used to compare the proportions between the two groups. A $p$ value of $\leq 0.05$ was considered as statistically significant.

\section{Results}

Included in this study are 67 patients (40 and 27 patients in the SI and LPF groups, respectively). The road traffic accident was the most common mode of injury $(67.16 \%)$ while the remaining cases were due to falling (32.84\%). The most common sacral fracture morphology was vertical (79.1\%), and APC-type II (47.7\%) was the most common injury followed by vertical shear (20.9\%) injury among the associated pelvic ring injuries. Different morphological patterns are detailed in Table 1 . The average follow-up period was 28.4 months (range, 26-49 months). Thirteen patients (19.4\%) required supplemental anterior stabilization (symphyseal plating, $\mathrm{n}=7$; pubic ramus screw, $\mathrm{n}=1$; and infix, $\mathrm{n}=5$ ) (Fig. 3). Infix removal was routinely performed as an outpatient procedure at 6-month followup after confirming radiological healing. The initial exfix application was required in nine patients, and distal femoral traction was applied in 14 patients which were removed at the time of definitive surgery.

Nine patients had associated spine trauma at other locations requiring surgical stabilization (lumbar, $n=4$; thoracic, $n=4$; and cervical, $n=1$ ) and 15 had other orthopedic injuries. None of the associated spine trauma patients had neurodeficit. Nine patients had other system injuries (head, $\mathrm{n}=3$; chest, $\mathrm{n}=4$; and abdomen, $\mathrm{n}=2$ ), and the mean ISS score was $23.5 \pm 11.6$. Three patients had neurodeficit at presentation, all associated with Denis zone III injury, and had undergone decompression (S1-4 laminectomy using high-speed burr). No open injuries were noticeable although four had associated Morel-Lavelle lesions, which necessitated open debridement.

\section{Sacroiliac group}

This group included 40 patients (28 males and $12 \mathrm{fe}$ males; 39 unilateral and one bilateral) with a mean age of $35.61 \pm 14.01$ years. The mean time from admission to definitive operative stabilization was $8.12 \pm 2.34$ days, and the mean ISS score was $22.24 \pm 2.65$. The average duration of surgery was $32.45 \pm 9.46$ hours, and blood loss was $96.16 \pm 15.34 \mathrm{~mL}$. Screw malposition occurred in one patient $(1.5 \%)$, and screw revision was done. According to the Majeed score, the functional outcome showed 23 (57.5\%), 11 (27.5\%), and 6 (15.0\%) with excellent, good, and fair results, respectively. The radiological outcome showed Matta scores as $26(65.0 \%), 11(27.5 \%)$, and 3

Table 1. The distribution of different injury patterns between the two groups

\begin{tabular}{|c|c|c|}
\hline Classification & $\begin{array}{l}\text { Sacroiliac screw } \\
\text { group }(\mathrm{n}=40)\end{array}$ & $\begin{array}{l}\text { Lumbopelvic fixation } \\
\text { group }(\mathrm{n}=27)\end{array}$ \\
\hline \multicolumn{3}{|l|}{ Denis } \\
\hline Zone 1 & 0 & 0 \\
\hline Zone 2 & 28 & 10 \\
\hline Zone 3 & 12 & 3 \\
\hline \multicolumn{3}{|l|}{ Roy-Camille } \\
\hline Type 1 & 0 & 0 \\
\hline Type 2 & 0 & 12 \\
\hline Type 3 & 0 & 2 \\
\hline \multicolumn{3}{|l|}{ Morphology } \\
\hline $\mathrm{H}$ & 0 & 1 \\
\hline $\mathrm{T}$ & 0 & 1 \\
\hline U & 0 & 1 \\
\hline Lambda & 0 & 0 \\
\hline Comminuted & 0 & 4 \\
\hline L-S dysmorphism & 0 & 1 \\
\hline \multicolumn{3}{|l|}{ Young \& Burgess } \\
\hline APC ॥ & 19 & 11 \\
\hline APC III & 7 & 6 \\
\hline LC II & 0 & 3 \\
\hline LC III & 3 & 4 \\
\hline Vertical shear & 11 & 3 \\
\hline \multicolumn{3}{|l|}{ Spino-pelvic dissociation } \\
\hline L5 transverse process fracture & 11 & 3 \\
\hline Bilateral vertical fracture & 0 & 3 \\
\hline High transverse fracture & 0 & 16 \\
\hline
\end{tabular}


(7.5\%) with excellent, good, and fair results, respectively (Table 2).

\section{Lumbopelvic fixation group}

This group had 27 patients (20 males and seven females; 24 unilateral and three bilateral) with a mean age of $39.31 \pm 15.42$ years. The mean time from admission to the definitive operative stabilization was $7.82 \pm 1.86$ days. The mean ISS score was $24.20 \pm 1.82$ with an average surgical duration of $102.12 \pm 12.45$ hours and a blood loss of $320.82 \pm 44.18 \mathrm{~mL}$. Three infections $(4.4 \%)$ took place wherein two required implant removal after fracture healing and one subsided with debridement. None of them required revision fixation. Two patients $(3 \%)$ had undergone implant removal for hardware prominence causing skin irritation. Out of the three patients with preoperative Gibbon's grade 3 neurological status, one had complete recovery while the other two remained the same. According to the Majeed score, the functional outcome showed 16 (59.3\%), 8 (29.6\%), and 3 (11.1\%) with excellent, good, and fair results, respectively. Nineteen $(70.4 \%)$ had maximum radiologic scoring with excellent reduction, six patients (22.2\%) had a good score, and two patients (7.4\%) had a fair reduction (Table 3 ). The mean postoperative pelvic incidence was $63.58^{\circ}$.

Age, the timing of surgery, ISS, duration of surgery, and blood loss were summarized in Table 4. Overall, six
Table 2. Functional outcome score (Majeed score) and radiological outcome score (Matta score) of sacroiliac screw group

\begin{tabular}{lrr} 
Grade & Majeed & Matta \\
Excellent & $23(57.5)$ & $26(65.0)$ \\
Good & $11(27.5)$ & $11(27.5)$ \\
Fair & $6(15.0)$ & $3(7.5)$ \\
\hline
\end{tabular}

Values are presented as number (\%).

Table 3. Functional outcome score (Majeed score) and radiological outcome score (Matta score) of lumbopelvic fixation group

\begin{tabular}{lcc} 
Grade & Majeed & Matta \\
\hline Excellent & $16(59.3)$ & $19(70.4)$ \\
Good & $8(29.6)$ & $6(22.2)$ \\
Fair & $3(11.1)$ & $2(7.4)$ \\
\hline
\end{tabular}

Values are presented as number (\%).

Table 4. Age, timing of surgery, ISS, duration of surgery, and blood loss of the two groups

\begin{tabular}{lcc} 
Variable & $\begin{array}{c}\text { Sacroiliac screw } \\
\text { group }\end{array}$ & $\begin{array}{c}\text { Lumbopelvic fixation } \\
\text { group }\end{array}$ \\
\hline Age (yr) & $36.62 \pm 11.42$ & $39.31 \pm 15.42$ \\
\hline Timing of surgery (day) & $8.12 \pm 2.34$ & $7.82 \pm 1.86$ \\
\hline ISS & $22.24 \pm 2.65$ & $24.20 \pm 1.82$ \\
\hline Duration of surgery (hr) & $32.45 \pm 9.46$ & $102.12 \pm 12.45$ \\
\hline Blood loss (mL) & $96.16 \pm 15.34$ & $320.82 \pm 44.18$ \\
\hline
\end{tabular}

Values are presented as mean \pm standard deviation ISS, Injury Severity Score.
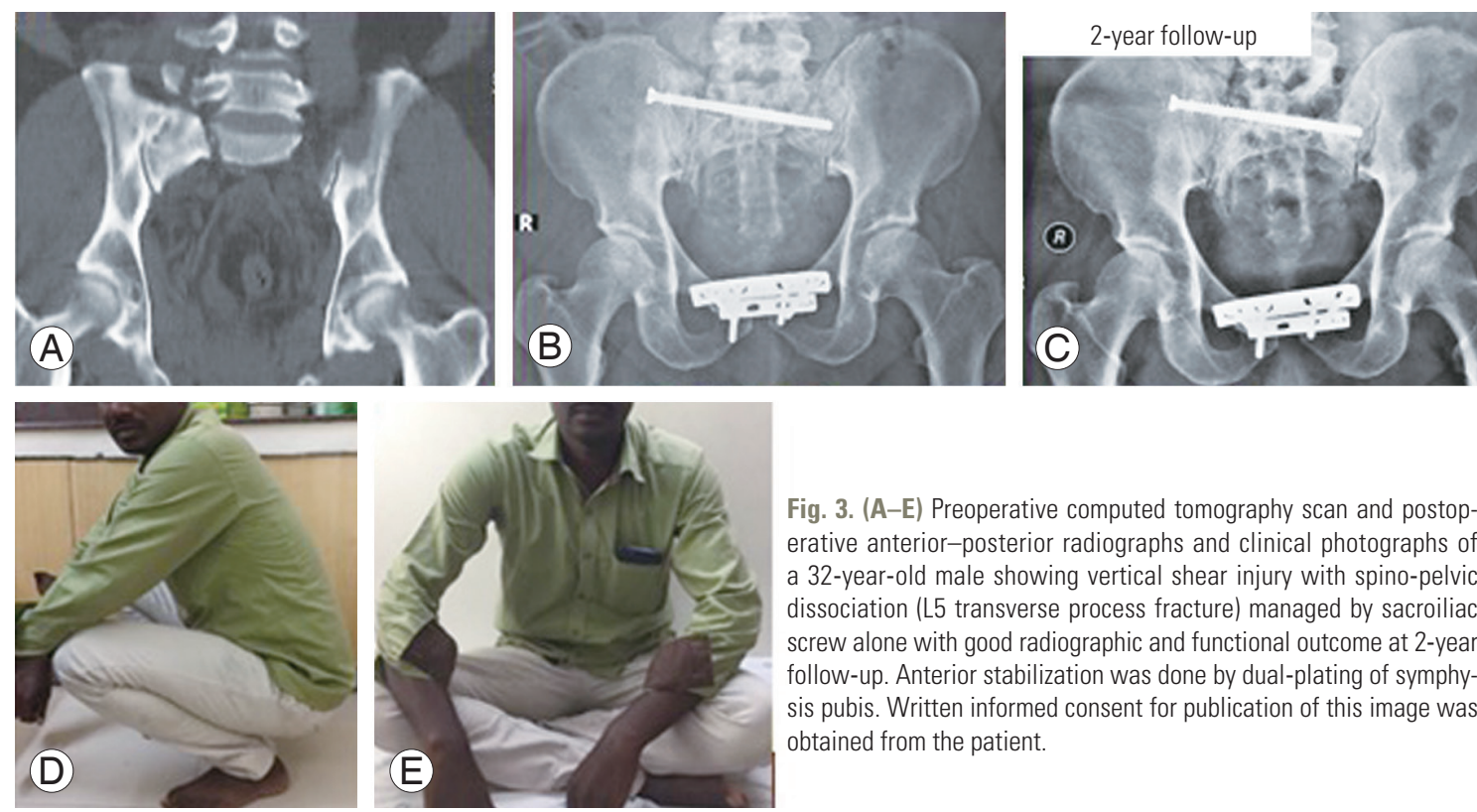

Fig. 3. (A-E) Preoperative computed tomography scan and postoperative anterior-posterior radiographs and clinical photographs of a 32-year-old male showing vertical shear injury with spino-pelvic dissociation (L5 transverse process fracture) managed by sacroiliac screw alone with good radiographic and functional outcome at 2-year follow-up. Anterior stabilization was done by dual-plating of symphysis pubis. Written informed consent for publication of this image was obtained from the patient. 
Table 5. Complications of the two groups

\begin{tabular}{lcc} 
Complication & $\begin{array}{c}\text { Sacroiliac screw } \\
\text { group }\end{array}$ & $\begin{array}{c}\text { Lumbopelvic fixation } \\
\text { group }\end{array}$ \\
\hline Infection & 0 & 3 \\
Screw malposition & 1 & 0 \\
\hline Implant prominence & 0 & 2 \\
\hline Loss of fixation & 0 & 0 \\
\hline Non-union & 0 & 0 \\
\hline Neuro-deterioration & 0 & 0 \\
\hline Total & $1(2.5)$ & $5(18.5)$ \\
\hline
\end{tabular}

Values are presented as number or number (\%).

Table 6. Comparison between Matta and Majeed grading between SI group and LPF group in vertical instability fractures

\begin{tabular}{lccc} 
& SI group (n=11) & LPF group (n=3) & $p$-value \\
Matta excellent rate & 45.0 & 63.6 & 0.06 \\
Majeed excellent rate & 57.5 & 54.5 & 0.41 \\
\hline
\end{tabular}

Values are presented as \%, unless otherwise stated.

SI, sacroiliac screw; LPF, lumbopelvic fixation.

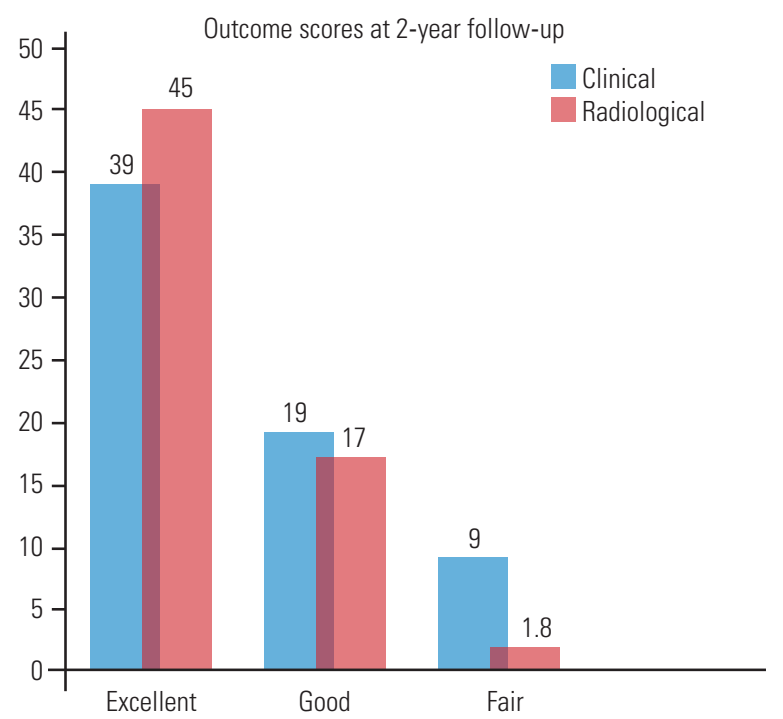

Fig. 4. Illustrative diagram showing outcome scores at 2-year follow-up.

complications (8.9\%), which is summarized in Table 5. The outcome scores are summarized in Fig. 4. A subgroup analysis between vertically unstable injuries in the two groups showed no significant difference in outcomes (Table 6).

\section{Discussion}

Fractures of the sacrum, although rare, with a reported incidence of approximately $45 \%$ of all pelvic fractures, can have a significant impact on the patient's quality of life as a consequence of chronic pelvic instability, deformity, prolonged recumbency, and neurological impairment [5]. The role of surgical management in promoting early mobilization and improved outcomes have been demonstrated $[11,12]$. However, no single management algorithm is applicable for all traumatic sacral fractures, and proper treatment has yet to be standardized. Despite the numerous salvage techniques described over the last 3 decades, recent advances in intraoperative imaging have led to the emergence of the SI screw and LPF as two major pillars for surgeons to lean on [1].

This study deliberately excluded isolated sacral fractures without pelvic ring disruption as it seldom creates any management dilemma in the minds of the treating surgeon. Even then, the sample size $(n=67)$ of this study was large enough compared with the majority of the literature on unstable sacral fractures [13-16]. Associated vertebral fracture was seen in $13.4 \%$ of patients as opposed to $44.26 \%$ by Park et al. [17] in his retrospective study on 71 patients. Although this appears low, a less likelihood for missed injuries exists in the institute of this study due to the polytrauma protocol being followed in which all patients had a whole-body CT scan and whole spine screening. Operative stabilization was performed for the vertebral fractures on the same day of definitive pelvic surgery. Moreover, it did not have any significant impact on treatment outcomes because none of them had any neurological deficit. Jazini et al. [2] reported an average ISS score of $27 \pm 13.6$ in his retrospective study of LPF on 32 patients, which is comparable to the score $(23.5 \pm 11.6)$ of the current study.

The incidence of spinopelvic dissociation in this study was $49.25 \%$, which is significantly higher than the previously reported rates of $3 \%-10 \%[17,18]$. This is probably due to the inclusion of only those patients having a combination of unstable sacral fractures and pelvic ring disruption, which invariably signifies a high-velocity trauma. Initial reports on LPF and triangular osteosynthesis have considered the presence of vertical instability with fracture comminution and/or spinopelvic dissociation as the only indication for these procedures $[19,20]$. However, a review of recent literature on the management of unstable 
fractures showed a major drift toward the routine use of LPF irrespective of the presence of fracture comminution or spinopelvic dissociation. The introduction of minimally invasive techniques expanded this further $[2,16]$. This study did not consider LPF imperative for all vertically unstable injuries unlike the aforementioned publications provided the fracture was noncomminuted, neurologically normal, and acceptable closed reduction could be preoperatively obtained (Fig. 3). Eleven patients in the SI group had vertical instability and all of them had a satisfactory outcome in the long term both clinically and radiologically compared with that achieved using LPF (Table 2). Moreover, surgical duration, intraoperative blood loss, and complications were also found to be lower in the SI group though a statistical analysis is not possible due to an unmatched cohort of patients in the two groups (Tables $5,6)$. A high mean ISS score $(23.5 \pm 11.6)$ also denotes the magnitude of injury, which would justify intervention with the least possible surgical trauma. In a retrospective analysis of 38 vertically unstable pelvic injuries treated by SI screw, Keating et al. [21] observed favorable outcomes with fewer complication rates. Similarly in 2015, the review by Iorio et al. [22] pointed out the advantages and effectiveness of the SI screw even in patients with vertical instability or spinopelvic dissociation. Complex fracture patterns like the $\mathrm{U}$ - and $\mathrm{H}$-shaped sacral fractures have also been managed successfully by an SI screw fixation with the satisfactory restoration of the pelvic parameters using a novel closed reduction technique described by Ruatti et al. [23] in 2013.

The outcome scores in the series of this study corresponded closely with previously reported similar studies. In a retrospective analysis of 22 patients with $\mathrm{AO}$ /type $\mathrm{C}$ posterior pelvic ring injuries treated by contemporary spinal instrumentation, Korovessis et al. [16] reported good and excellent Majeed and Matta scores in $81.81 \%$ and $95.45 \%$ of the patients, respectively. With a sample size almost three times higher than a study of Korovessis et al. [16], the functional and radiological scores of this study were comparable ( $86.57 \%$ and $92.54 \%$, respectively).

The complication rates of this study were very low (8.9\%) as opposed to the existing publications on the SI screw as well as LPF $[13,24]$. All the surgeries being performed by the senior author as well as appropriate patient selection and precautionary measures taken in screw head recession may have helped the cause. Moreover, the subject of this study is comprised of patients in the younger age group (mean, 35.61 \pm 14.01 years), which may have reduced the complications related to implant purchase and wound healing. The complication rate was higher in the LPF group although the number is too small for statistical analysis. This could partly be attributed to injury factors as well because all patients had sustained a high-velocity trauma. Patients with neurodeficit all belonged to zone III injury, which was consistent with the findings of Denis et al. [5] in his retrospective analysis of 236 patients. Regardless of the role of decompression surgery in neurodeficit, direct decompression was performed in all patients $(n=3)$ wherein one had a complete recovery [25-27].

Although this study was limited by its retrospective design, it would be rather justified by the rarity of these injuries as evidenced by smaller sample sizes in the existing literature $[2,11,14,16]$. It is also agreeable that the sample size of the current study is inadequate for power analysis and has a high risk for type-II error to occur. The series of this study is difficult if not impossible to compare and draw a conclusion because the subject included varying patterns of complex sacral fractures forming an unmatched cohort of patients managed by two separate techniques. A relatively younger age group of the patient population may restrict the applicability of inference in older, osteoporotic patients with similar injuries. A prospective study design with matched study groups and randomization is ideally needed for better interpretation of conclusions. Through this study, it is believed that LPF is not always the rule in unstable sacral fracture management. Although it offers early weight-bearing compared with SI screw fixation, this is often precluded by associated injuries in the form of intra-articular fractures of the lower limb or other systemic injuries.

\section{Conclusions}

Unstable sacral fractures can be effectively managed with percutaneous SI screw including vertically unstable injuries by paying strict attention to preoperative patient selection in terms of fracture pattern and comminution, neurodeficit, and closed reduction techniques thereby reducing the complications associated with LPF. Furthermore, LPF can be reserved for comminuted fractures with vertical instability, unacceptable closed reduction, associated neurodeficit, lumbosacral dysmorphism, and high transverse fractures. 


\section{Conflict of Interest}

No potential conflict of interest relevant to this article was reported.

\section{Author Contributions}

Conceptualization: APS, KRR, RP, RMK, SR; data curation: APS, SVA; formal analysis: all authors; methodology: APS, KRR, RP; software: APS; supervision: KRR, RP, SVA; validation: KRR, RP; visualization: SVA; project administration: RMK, SR; and writing-original draft and final approval of the version: all authors.

\section{References}

1. Verbeek DO, Routt ML Jr. High-energy pelvic ring disruptions with complete posterior instability: contemporary reduction and fixation strategies. J Bone Joint Surg Am 2018;100:1704-12.

2. Jazini E, Weir T, Nwodim E, et al. Outcomes of lumbopelvic fixation in the treatment of complex sacral fractures using minimally invasive surgical techniques. Spine J 2017;17:1238-46.

3. Durkin A, Sagi HC, Durham R, Flint L. Contemporary management of pelvic fractures. Am J Surg 2006;192:211-23.

4. Gibbons KJ, Soloniuk DS, Razack N. Neurological injury and patterns of sacral fractures. J Neurosurg 1990;72:889-93.

5. Denis F, Davis S, Comfort T. Sacral fractures: an important problem: retrospective analysis of 236 cases. Clin Orthop Relat Res 1988;227:67-81.

6. Roy-Camille R, Saillant G, Gagna G, Mazel C. Transverse fracture of the upper sacrum: suicidal jumper's fracture. Spine (Phila Pa 1976) 1985;10:838-45.

7. Strange-Vognsen HH, Lebech A. An unusual type of fracture in the upper sacrum. J Orthop Trauma 1991;5:200-3.

8. Burgess AR, Eastridge BJ, Young JW, et al. Pelvic ring disruptions: effective classification system and treatment protocols. J Trauma 1990;30:848-56.

9. Matta JM, Tornetta P 3rd. Internal fixation of unstable pelvic ring injuries. Clin Orthop Relat Res 1996;(329):129-40.

10. Majeed SA. Grading the outcome of pelvic fractures. J Bone Joint Surg Br 1989;71:304-6.
11. Browner BD, Cole JD, Graham JM, Bondurant FJ, Nunchuck-Burns SK, Colter HB. Delayed posterior internal fixation of unstable pelvic fractures. J Trauma 1987;27:998-1006.

12. Gribnau AJ, van Hensbroek PB, Haverlag R, Ponsen KJ, Been HD, Goslings JC. U-shaped sacral fractures: surgical treatment and quality of life. Injury 2009;40:1040-8.

13. Bellabarba C, Schildhauer TA, Vaccaro AR, Chapman JR. Complications associated with surgical stabilization of high-grade sacral fracture dislocations with spino-pelvic instability. Spine (Phila Pa 1976) 2006;31(11 Suppl):S80-8.

14. Sagi HC, Militano U, Caron T, Lindvall E. A comprehensive analysis with minimum 1-year follow-up of vertically unstable transforaminal sacral fractures treated with triangular osteosynthesis. J Orthop Trauma 2009;23:313-9.

15. Williams SK, Quinnan SM. Percutaneous lumbopelvic fixation for reduction and stabilization of sacral fractures with spinopelvic dissociation patterns. J Orthop Trauma 2016;30:e318-24.

16. Korovessis P, Spastris P, Syrimpeis V, Tsekouras V, Petrou $S$. Contemporary less invasive spinal instrumentation for AO C-type posterior pelvic ring injuries. Eur Spine J 2020;29:2521-33.

17. Park YS, Baek SW, Kim HS, Park KC. Management of sacral fractures associated with spinal or pelvic ring injury. J Trauma Acute Care Surg 2012;73:239-42.

18. Dussa CU, Soni BM. Influence of type of management of transverse sacral fractures on neurological outcome: a case series and review of literature. Spinal Cord 2008;46:590-4.

19. Schildhauer TA, Josten C, Muhr G. Triangular osteosynthesis of vertically unstable sacrum fractures: a new concept allowing early weight-bearing. J Orthop Trauma 1998;12:307-14.

20. Sagi HC. Technical aspects and recommended treatment algorithms in triangular osteosynthesis and spinopelvic fixation for vertical shear transforaminal sacral fractures. J Orthop Trauma 2009;23:354-60.

21. Keating JF, Werier J, Blachut P, Broekhuyse H, Meek $\mathrm{RN}, \mathrm{O}$ 'Brien PJ. Early fixation of the vertically unstable pelvis: the role of iliosacral screw fixation of the posterior lesion. J Orthop Trauma 1999;13:107-13.

22. Iorio JA, Jakoi AM, Rehman S. Percutaneous sacroiliac screw fixation of the posterior pelvic ring. Orthop 
Clin North Am 2015;46:511-21.

23. Ruatti S, Kerschbaumer G, Gay E, Milaire M, Merloz $\mathrm{P}$, Tonetti J. Technique for reduction and percutaneous fixation of $\mathrm{U}$ - and $\mathrm{H}$-shaped sacral fractures. Orthop Traumatol Surg Res 2013;99:625-9.

24. Tonetti J, van Overschelde J, Sadok B, Vouaillat H, Eid A. Percutaneous ilio-sacral screwinsertion: fluoroscopic techniques. Orthop Traumatol Surg Res 2013;99:965-72.
25. Vaccaro AR, Kim DH, Brodke DS, et al. Diagnosis and management of sacral spine fractures. Instr Course Lect 2004;53:375-85.

26. Mehta S, Auerbach JD, Born CT, Chin KR. Sacral fractures. J Am Acad Orthop Surg 2006;14:656-65.

27. Ayoub MA. Displaced spinopelvic dissociation with sacral cauda equina syndrome: outcome of surgical decompression with a preliminary management algorithm. Eur Spine J 2012;21:1815-25. 